Published by the University of KwaZulu-Natal https://journals.ukzn.ac.za/index.php/JICBE (C) Creative Commons With Attribution (CC-BY) Journal of Inclusive cities and Built environment. Vol. 2 Issue 1

How to cite: B.N. Rumutsa and N.S Nethengwe. 2022. An early warning system for malaria in Mopani District: Divergent or Convergent approaches. Conference Proceedings for International Symposium on Inclusive-Cities: Achieving Inclusive Cities Through A Multidisciplinary Approach, 2021 28-30 June. Journal of Inclusive cities and Built environment. Vol. 2 Issue 1, Pg 9-12.

\title{
AN EARLY WARNING SYSTEM FOR MALARIA IN MOPANI DISTRICT: DIVERGENT OR CONVERGENT APPROACHES
}

\author{
By B.N. Rumutsa and N.S Nethengwe
}

Published 31 January 2022

\begin{abstract}
Abstract. Malaria is a tropical climate-change concatenated biological hazard that may, like any other hazard, lead to a disaster and requires a multidisciplinary divergent approach. This research was carried out in Mopani District of South Africa. It sought find out whether the existing early warning system in Mopani District is adopting a convergent or divergent approach. Subsequently, this was to assist in developing a tool that covers the loopholes in the existing system to further mitigate malaria transmissions. The study took a mixed approach. Data was collected from 381 selected participants through in-depth interviews, a survey, and a focus group discussion. Multiple sampling techniques were used in this study. In-depth interviews respondents were selected through snowballing, questionnaire survey respondents were sampled randomly, while for the discussants in the focus group discussion were purposively sampled. The study applied constructivist grounded theory to analyse qualitative data and to generate theory. Results of the study show that people in Mopani District predict the malaria season onset by forecasting rainfall using various indigenous knowledge-based indicators. The rainfall indicators mentioned by participants in the study were used to develop an early warning system. In the design of the system, Apache Cordova, JDK 1.8, Node JS, and XAMPP software were used. The study recommends malaria management and control key stakeholders to adopt the developed early warning system to further mitigate malaria transmission in Mopani District.
\end{abstract}

KEY WORDS Malaria, Indigenous knowledge, risk reduction, early warning system.

Brenda Nyeverwai Rumutsa: University of Venda, University Street, 0950, Thohoyandou. E-mail: brendarumucha@yahoo.com Nthaduleni Samuel Nethengwe: University of Venda, University Street, 0950, Thohoyandou. 


\section{INTRODUCTION}

In South Africa, the contemporary early warning system is proving to be inadequate in helping both rural and urban communities as evidenced by continuous malaria outbreaks. Sometimes affected communities fail to cope with their capacities, hence it cannot be a misnomer calling such an event a disaster. The Department of Health (DoH) of Mopani District acknowledged that it is failing at the prevention stage in its approach for malaria risk reduction (MRR). A divergent multidisciplined integrated Early Warning System (EWS) can assist as it is a safety critical-system that helps for hazards (Löwe et al., 2013).

A divergent approach explores all possible solution while convergent approaches focuses on a single well established solution to a problem. Early warning systems require a divergent approach as they are more than just prediction since they prevent hazards from turning into disasters. It is an essential tool that builds the capacities of communities to reduce their vulnerability to hazards or disasters. To be effective it has to be inclusive and community centred (Macherera and Chimbari 2016). EWSs' encompass a set of capacities required to generate and disseminate meaningful warnings when there is still ample time for those being threatened by the hazard to prepare or take action to minimize the possibility of harm or loss (IFRC., 2012). An EWS should integrate four elements, which are - (i) knowledge of the risks faced; (ii) technical monitoring and warning service; (iii) dissemination of meaningful warnings to those at risk; and (iv) public awareness and preparedness for action (ISDR 2006). Failure in any one of the elements can result in the failure of the whole system (Macherera and Chimbari 2016; Karanath and Dashora 2014; Twigg 2015; Simonovic 2010).

\section{SETTINGS AND METHODS}

This study was carried out in Mopani District of South Africa between the year 2017 to 2020. The local municipalities involved are Ba-Phalaborwa, Greater Tzaneen, Greater Letaba, and Maruleng.
Data was collected from 381 selected participants through in-depth interviews, a survey and a focus group discussion. Multiple sampling techniques were used in this study. In-depth interviews respondents were selected through snowballing, questionnaire survey respondents were sampled randomly, while for the discussants in the focus group discussion were purposively sampled. The study applied constructivist grounded theory to analyse qualitative data and to generate theory. Statistical Package for Social Sciences (SPSS) version 23.0 was used for analysing quantitative data. The systems approach for disaster management and the framework for elements of an integrated EWS (ISDR 2006) were used to explore the nature of the existing malaria early warning system in Mopani District. To develop the early warning system Apache Cordova, JDK 1.8, Node JS, and XAMPP software were used.

\section{RESULTS}

\subsection{NATURE OF THE EWS IN MOPANI DISTRICT (DIVERGENT OR CONVERGENT APPROACH)}

An analysis of all possible sources of problems within the existing system was done by examining each individual element in consistent with the systems approach to managing disasters, (Simonovic'2010). The theory brings out that an integrated system can be more effective than unconnected elements operating autonomously. From the empirical results, it was found out that even though all the elements of an early warning system were present in the system in Mopani District, there were some loopholes in it.

The results show that the majority $(69 \%)$ of the participants were aware of the malaria hazard in the area. About 18\% indicated that there was no malaria risk in their area and $13 \%$ had no idea if there was any risk of malaria at all. The results of the study show that the existing EWS emphasizes monitoring activities. The responsible institutions for malaria control consider the detection of malaria season by the number of recorded cases. The results also demonstrated that the element of dissemination and communication was present in the existing EWS. Both in-depth interviews and survey results enlightened the researchers that even though dissemination was part of the elements, information was not reaching all intended people. A larger percentage, thus $61 \%$ of the participants indicated that they had received alert messages while $39 \%$ had never received any alerts. The existing EWS is expert-driven and it emphasizes on a convergent approach of monitoring the number of malaria cases detected hence it is more of reactionary. It was also noted from the results of the study that the EWS is exclusive as Mopani District rural and urban communities have a minimum role in the malaria control program. Reliance on spraying Dichlorodiphenyltrichloroethane (DDT) and pyrethroids has also added on to excluding communities since experts in the malaria control program simply expect members to follow the given instructions and orders. This was brought out when one of the key informants emphasized that;

"The community members should just understand and practice what we tell them to do. If they do that, then malaria can end".

From the empirical results, this has led to a relatively large number of people remain relaxed as they do nothing upon receiving the malaria alert messages.

\subsection{DEVELOPING AN EARLY WARNING SYSTEM}

To develop an inclusive EWS, the researchers first took an inventory of both scientific and IK existing in the study area. It was then decided on the information to be harnessed for the EWS. Rainfall based indicators for malaria season onset mentioned by the study participants were considered. The researchers then used information communication technology (ICT) as a platform for the development of an integrated EWS. This was consistent with Lodhi and Mikulecky, (2011), who reveals that ICT enhances the blending of indigenous, scientific, and technical knowledge. Studies (Karanath and Dashora, 2014; Lodhi and Mikulecky, 2011) reported that ICT can be used as 
the basic foundation of networking arrangements that assist immensely in meeting the desired objectives of an EWS. Rainfall indicators measures grounded in the data that was collected in the area of study were used in the EWS.

The predictive capacity was enhanced by integrating indigenous knowledge-based indicators with scientific data using Information and Communication Technology (ICT) as a platform for integration in the design of the system. The Malaria Early Warning System App was developed using Apache Cordova, JDK 1.8, Node JS, and XAMPP software. Elements of an effective early warning system (such as risk knowledge, response capacity and monitoring and warning services) were used to for validation. The following figures show the homepage and admin panel of the developed EWS.

Figure 1: Administrators' login portal
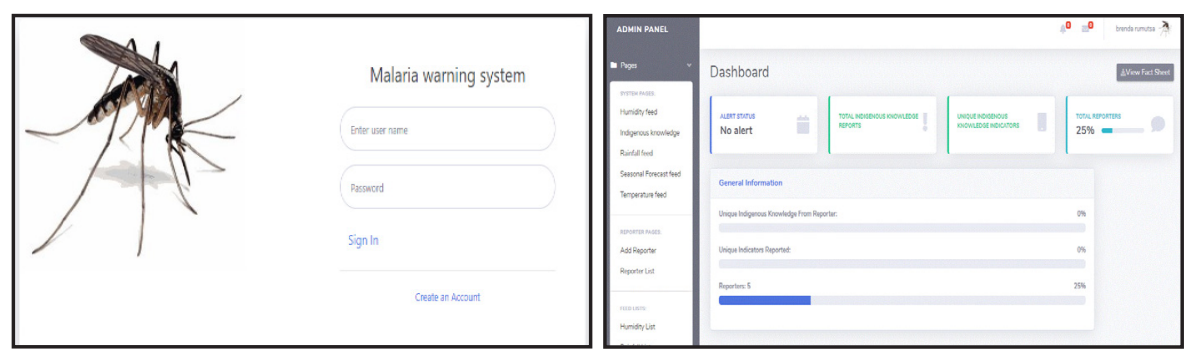

Source: Rumutsa 2020

The administrator of the system and community reporters are also to enter data. If data is not fed into the system by communities or by the administrators an alert cannot be raised hence community participation is important. The communities feed in indigenous knowledge while the administrators feeding scientific knowledge hence the two forms of knowledge are integrated in the system. This means that alerts are triggered as a result of the data entered by both the community and the administrator and no one between the two groups has the power to influence the triggering of a warning as the system does the monitoring on its own.

\section{DISCUSSION}

It was found out that the institutions responsible for alerting communities on malaria in Mopani District are doing their best. However, the issuance of alerts on its own is not useful unless it is complemented by an integrated system with different components that enable people to deal with an impending danger. Such action is supported by Lenton (2013) who mentions that risk knowledge to a large extent can provoke action among communities hence members need to know common hazard risks in their areas. This converges with what is recommended by ISDR (2006) that there is a need to effectively disseminate messages and warnings to ensure that there is a constant state of preparedness among those that are facing hazard risks. When people know their risks they can cushion themselves. According to Sättele et al., (2015) warning people at risk avoids losses.

A convergent approach of detecting the malaria season by the number of recorded cases is being adopted of which some people would have been already affected by the biological hazard. Detection of a rise in malaria cases cannot be part of prevention as people would have already been affected (Rumutsa 2020). An early warning refers to "a thing that tells you in advance that something serious or dangerous is going to happen" (Oxford English Dictionary, 2015). The system is reactive and not proactive of which with an effective EWS in place contrary to early detection, there is an attempt to predict epidemics before an unusual transmission is detected (Teklehaimanot et al., 2004; Macherera, et al., 2015). People are being excluded more so they have been conditioned to just waiting for assistance. Taking communities as passive recipients in handling the health hazard could be contributing to a failure in preventing malaria outbreaks. As such, individuals cannot be regarded as passive recipients of DRR actioning ( Twigg 2015) they should be included in dealing with an impending danger.

\section{CONCLUSIONS}

Malaria risk reduction interventions in Mopani District encompass a convergent approach. Outbreaks due to the biological hazard are considered an exclusive mandate of the Department of Health, of which by nature management activities are overarching and multidisciplinary. The malaria management and control key stakeholders may consider adopting the practical Malaria Early Warning System (MEWS) that was developed in this study to complement the existing malaria control initiatives. The tool is functional and will enhance proactiveness, and early forecasting of the malaria season, that is, 3 months or more before the time when outbreaks occur. It could help in further mitigating the malaria hazard as it promotes the inclusion of communities and promotes an inclusive multidisciplinary divergent approach. It was specifically developed considering the existing challenge of persistent malaria transmissions in Mopani District. It will help the communities to prepare and act in sufficient time to reduce the possibility of harm or loss. This study, therefore, concludes that it is feasible to develop a tailor-made early warning system that integrates indigenous and scientific knowledge using Information communication and technology as a platform for the integration. Gaps in the existing MEWS for further malaria mitigation can be covered through allowing community participation in MRR. 


\section{REFERENCES}

IFRC. 'Community early warning systems. Guiding principles', $p$. 84.(2012).

ISDR. 'Developing Early Warning Systems : A Checklist', Third International Conference on Early Warning, (March), pp. 1-13.(2006).

Karanath Anup, Dashora Lalit Kumar, R. U. 'Review of Multi Hazard Early Warning System of Visakhapatnam ( India ). (2014).

Lenton, T. M. 'What early warning systems are there for environmental shocks?', Environmental Science \& Policy, 27, pp. S60-S75. (2013).

Lodhi, M.S. and Mikulecky, P.,. Motives and modes of indigenous knowledge management. In Proceedings of the 2nd International Conference on Urban Sustainability, Cultural Sustainability, Green Development, Green Structures and Clean Cars, Prague (pp. 89-94). (2011).

Löwe, P., Wächter, J., Hammitzsch, M., Lendholt, M., Häner, R., Moßgraber, J. and Sabeur, Z., The Evolution of Disaster Early Warning Systems in the TRIDEC Project. In The Twentythird International Offshore and Polar Engineering Conference. International Society of Offshore and Polar Engineers. (2013).

Macherera, M., Chimbari, M. J. and Mukaratirwa, S. 'Indigenous environmental indicators for malaria: A district study in Zimbabwe', Acta Tropica. Elsevier B.V., 175, pp. 50-59. (2015).

Macherera, M. and Chimbari, M. J. 'A review of studies on community based early warning systems', Jàmbá: Journal of Disaster Risk Studies, 8(1), p. 11 (2016).

Oxford English Dictionary. Oxford Advanced Learner's Dictionary, International Student's Edition.Oxford University Press. (2015).
Rumutsa,B., N.: Integrating indigenous and scientific knowledge in community based early warning system development for climaterelated malaria risk reduction in Mopani District of South Africa. (Unpublished doctoral thesis). University of Venda, Thohoyandou (2021)

Simonovic, S.P.,. Systems approach to management of disasters: methods and applications. John Wiley \& Sons. London. (2010).

Sättele, M., Bründl, M. and Straub, D.'Reliability and effectiveness of early warning systems for natural hazards : Concept and application to debris flow warning', Reliability Engineering and System Safety. Elsevier, 142, pp. 192-202. (2015)

Teklehaimanot, H. D. et al. 'Weatherbased prediction of Plasmodium falciparum malaria in epidemic-prone regions of Ethiopia II. Weather-based prediction systems perform comparably to early detection systems in identifying times for interventions', Malaria Journal, 3(3). (2004).

Twigg, J.,. Disaster risk reduction. London: Overseas Development Institute, Humanitarian Policy Group, pp. 170-175. (2015). 